\title{
The use of standard calendar software by individuals with acquired brain injury and cognitive complaints: a mixed methods study
}

\author{
Citation for published version (APA):
}

de Joode, E. A., Proot, I., Slegers, K., van Heugten, C., Verhey, F., \& van Boxtel, M. (2012). The use of standard calendar software by individuals with acquired brain injury and cognitive complaints: a mixed methods study. Disability and Rehabilitation: Assistive Technology, 7(5), 389-398. https://doi.org/10.3109/17483107.2011.644623

Document status and date:

Published: 01/01/2012

DOI:

10.3109/17483107.2011.644623

Document Version:

Publisher's PDF, also known as Version of record

\section{Document license:}

Taverne

Please check the document version of this publication:

- A submitted manuscript is the version of the article upon submission and before peer-review. There can be important differences between the submitted version and the official published version of record.

People interested in the research are advised to contact the author for the final version of the publication, or visit the DOI to the publisher's website.

- The final author version and the galley proof are versions of the publication after peer review.

- The final published version features the final layout of the paper including the volume, issue and page numbers.

Link to publication

\footnotetext{
General rights rights.

- You may freely distribute the URL identifying the publication in the public portal. please follow below link for the End User Agreement:

www.umlib.nl/taverne-license

Take down policy

If you believe that this document breaches copyright please contact us at:

repository@maastrichtuniversity.nl

providing details and we will investigate your claim.
}

Copyright and moral rights for the publications made accessible in the public portal are retained by the authors and/or other copyright owners and it is a condition of accessing publications that users recognise and abide by the legal requirements associated with these

- Users may download and print one copy of any publication from the public portal for the purpose of private study or research.

- You may not further distribute the material or use it for any profit-making activity or commercial gain

If the publication is distributed under the terms of Article $25 \mathrm{fa}$ of the Dutch Copyright Act, indicated by the "Taverne" license above, 


\section{The use of standard calendar software by individuals with acquired brain injury and cognitive complaints: a mixed methods study}

Elisabeth de Joode, Ireen Proot, Karin Slegers, Caroline van Heugten, Frans Verhey \& Martin van Boxtel

To cite this article: Elisabeth de Joode, Ireen Proot, Karin Slegers, Caroline van Heugten, Frans Verhey \& Martin van Boxtel (2012) The use of standard calendar software by individuals with acquired brain injury and cognitive complaints: a mixed methods study, Disability and Rehabilitation: Assistive Technology, 7:5, 389-398, DOI: 10.3109/17483107.2011.644623

To link to this article: https://doi.org/10.3109/17483107.2011.644623

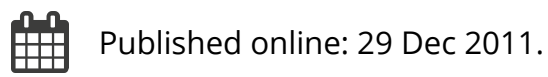

Submit your article to this journal ๘

山ll Article views: 384

Q View related articles $\square$

Citing articles: 6 View citing articles $[3$ 


\title{
The use of standard calendar software by individuals with acquired brain injury and cognitive complaints: a mixed methods study
}

\author{
Elisabeth de Joode ${ }^{1}$, Ireen Proot ${ }^{2}$, Karin Slegers ${ }^{3}$, Caroline van Heugten ${ }^{1,4}$, Frans Verhey ${ }^{1}$ \& \\ Martin van Boxtel ${ }^{1}$ \\ ${ }^{1}$ Psychiatry and Neuropsychology, Maastricht University, Maastricht, Netherlands, ${ }^{2}$ Clinical Genetics/Governor Kremers Centre, \\ Maastricht University, Maastricht, Netherlands, ${ }^{3}$ Centre for User Experience Research, Katholieke Universiteit Leuven, Leuven, \\ Belgium, and ${ }^{4}$ Neuropsychology and Psychopharmacology, Maastricht University, Maastricht, Netherlands
}

Purpose: To explore the actual use of standard calendar software by people with acquired brain injury $(\mathrm{ABI})$ and healthy individuals. Method: Mixed methods design with qualitative and quantitative analyses of the respondents' use of calendar software. Fifteen individuals with $A B I$ and 15 healthy participants were enrolled. Participants were asked to execute five consecutive tasks using standard calendar software, which resembled everyday use of an electronic calendar. Results: The core processes "task execution" and "information processing" were influenced by internal factors (cognitive and emotional processes and fatigue) as well as environmental factors (software features and distractions). Results obtained by qualitative and quantitative methods showed similar reaction patterns in both groups. However, ABI patients had more cognitive problems and showed stronger emotions during task performance than healthy participants. Healthy participants were more successful and needed less time and mental effort to perform a task. Conclusions: Although ABI patients were able to use standard calendar software, they became upset more easily, needed more effort, became tired sooner and more suddenly. Strategies to support ABI patients in the use of calendar software are suggested from multi-disciplinary perspectives.

Keywords: Cognitive rehabilitation, stroke, traumatic brain injury

\section{Introduction}

Acquired brain injury (ABI), such as stroke and traumatic brain injury, can cause persistent cognitive deficits in afflicted individuals. Most of these patients have impairments of memory, attention and executive functioning [1-3]. To compensate for these cognitive problems, people with ABI often use traditional aids, such as notebooks and diaries, which

\section{Implications for Rehabilitation}

- A user-centred approach is necessary when designing dedicated calendar software for acquired brain injury (ABI) patients with cognitive deficits.

- Training ABI patients in the use of assistive technology should focus on the influence of person-related factors such as cognitive and emotional processes and fatigue and environmental factors such as software features and distractions.

- In order to conceive and realize user-centred solutions for AT use in cognitive rehabilitation, a strong multidisciplinary input is necessary.

may help them to structure their daily life activities and keep track of appointments [4]. The use of electronic devices could offer even more potential benefits to these patients, not only because of their special functions, such as a reminder function, but also because dedicated software can be used on a wide range of hardware platforms, such as a Smartphone or personal digital assistant (PDA). These portable devices can store large amounts of information that may support daily activities of people with ABI $[5,6]$. A recent review described the efficacy of pagers, PDAs and other types of assistive technology (AT) to support cognitive functions [7]. The authors concluded that PDAs could indeed improve daily life functioning by enhancing independent behaviour [6] and increasing the number of achieved goals set by patients with ABI [8], but solid evidence is still limited.

Although both clinicians and potential users have expressed their enthusiasm about the possibilities of AT for patients with ABI, AT and more specifically calendar software have to date not been widely used in cognitive rehabilitation

Correspondence: Dr. Caroline van Heugten, Psychiatry and Neuropsychology, Maastricht University, Maastricht, Netherlands.

E-mail: c.vanheugten@maastrichtuniversity.nl

(Accepted November 2011) 
$[9,10]$. One explanation for what we would like to call this "implementation lag" could stem from the assumptions that clinicians and potential users have about AT, e.g. that it may take patients long to adapt to AT, or that the standard software installed on non-customized devices might not be optimal for use by brain-injured people $[9,11,12]$.

Barriers to the use of calendar software by people with $\mathrm{ABI}$ could also relate to the kind of cognitive deficits that occur most commonly. For example, individuals with impaired selective attention may experience difficulties when looking at feature-rich content on a computer screen. Individuals with memory impairments may have difficulty learning and keeping track of the successive steps used to enter an appointment in the calendar, while individuals with a dysexecutive syndrome may have problems with impulse control and error monitoring, abilities which are considered to be essential at all levels of computer use [13]. However, such assumptions have so far never been investigated systematically. It is therefore not only important to assess the user needs regarding AT [14], but also to assess the actual use of AT by people with ABI, in order to identify issues that need to be dealt with to enhance the implementation of AT in cognitive rehabilitation.

The purpose of this study was to determine the suitability of standard calendar software for brain-injured patients. We conducted a study in which, we systematically observed the actual use of calendar software by patients with ABI and by healthy individuals in terms of performance and results, and in terms of perceived experiences. Earlier research in the field of rehabilitation has shown that a combined qualitative and quantitative approach can be beneficial, and that patients' attitudes, thoughts and motivation regarding the rehabilitation process can guide the development and improvement of rehabilitation methods $[15,16]$. We therefore developed a mixed methods design using quantitative and qualitative methods to explore, describe and reflect on the experiences and opinions of potential users of AT. The qualitative method allowed us to collect rich, in depth information about the experience of the participants during the use of calendar software. The quantitative method enabled us to compare patients with ABI and healthy individuals with respect to the speed and success rate of task execution and the amount of effort users reported when completing the tasks.

\section{Methods}

\section{Participants}

Thirty participants were recruited for the study, 15 patients with $\mathrm{ABI}$ and 15 healthy participants. General inclusion criteria for both groups were age between 18 and 65 years and being able to operate a computer. Participants were to have basic knowledge of computer use and no or only limited experience with standard calendar software.

Participants with ABI were recruited through posters in rehabilitation centres, and through rehabilitation psychologists who were asked to screen their patient population for eligible participants. Patients all had suffered an ABI and completed their treatment in a rehabilitation centre. Patients had to have persistent complaints about their memory, attention or planning capabilities, as assessed by self-report. The presence of other neurological conditions (e.g. dementia or Multiple Sclerosis) was an exclusion criterion. The medical ethics board approved the current study, and all participants gave informed consent.

Nine healthy participants were partners of the patients; the other six were recruited from a volunteer database of the Department of Psychiatry and Neuropsychology at Maastricht University. Healthy participants were excluded if they reported cognitive complaints or had suffered neurological damage in the past.

\section{Procedures and measures}

Data were collected during a two-hour visit at the participants' homes. The investigator (EdJ) brought a laptop with a separate keyboard and mouse to be used by the participant. A semi-structured interview was used to discuss questions concerning prior experience with computers (e.g. number of hours a week).

Participants started to use the calendar software under guidance of the investigator, but no additional explanation about the use of the software was provided. Next, participants were asked to execute five consecutive tasks common to the everyday use of an electronic calendar using standard calendar software (Windows XP version of Microsoft Office Outlook 2003). The assignments included scheduling an appointment with a general practitioner (GP) at a particular date and time, planning a shopping trip and social visits and entering recurring appointments (see Appendix 1 for a full overview of all tasks). The task instructions were available to participants throughout the task.

After all five tasks had been completed, the participants' experiences were discussed in a second semi-structured interview in which the respondents were presented with statements. Participants were also asked if their opinion about the use of the software had changed after the session.

\section{Qualitative data collection}

Qualitative data were obtained by audio-visually recording all the participants' actions and verbalizations. Participants were asked to "think aloud" as much as possible while executing a task, and if necessary they were reminded of this by the investigator. The actions on the computer (screen capture and key input) as well as the verbal and facial non-verbal responses were recorded using Screenflow software (version 1.5.4 for Mac OSX). In addition, the investigator observed and took notes, and assisted the participants only if it was obvious that they could not proceed with the task without help, or if they accidentally quit the program.

\section{Quantitative data collection}

The differences in cognitive functioning between the participants with $\mathrm{ABI}$ and the healthy participants were documented by screening cognitive functioning with two neuropsychological tests. Episodic verbal memory was tested with the Rey Visual Verbal Learning Test [17]. The total score on all five learning trials in which a list of 15 words had to be 
remembered was calculated with a higher score indicating better performance. Executive functioning was tested with the Concept Shifting Test [18], by calculating the difference in time needed to complete part C (in which two tasks needed to be performed at the same time, i.e. continual concept switching) compared to part B (in which no concept shifting is necessary). A larger time difference indicates worse executive functioning. Cognitive complaints were assessed in both groups using the Cognitive Failure Questionnaire (CFQ [19]). The CFQ consists of 25 questions, and participants can rate the frequency of their daily cognitive problems on a 5-point scale (ranging from "never" to "very often"). The total scoring range is $0-100$ (a higher score denoting more daily cognitive failures). Educational level was rated according to a standard classification system [20].

Outcome measures for the five computer tasks were speed of task execution and success rate. Speed was measured as the amount of time needed from the moment the participant read the assignment until they indicated that the task had been completed, or until the investigator aborted the task as no further progress was expected. Success rate for the groups was defined as the number of participants who successfully completed a task as compared to the number of participants who failed, accumulated over the total of five tasks. Success was defined as the completion or semi-completion (i.e. either using the correct method or the correct information, but not both) of the task. Failure was defined as non-execution of the task or essential parts of it, or as abortion of the task.

After each task, the participants indicated the amount of effort needed to perform the task on the Mental Effort Scale [21]. This scale measures the subjective experience of mental effort during task execution. It consists of a 150-mm long vertical scale, which is marked on nine points along the scale with a verbal description of the amount of effort, ranging from "no effort" to "extreme effort" (see Appendix 2).

After the test session, the semi-structured interview focused on statements about the ease of use of the calendar software. Participants indicated their agreement with each statement on a Likert scale, ranging from 1 (disagree) to 5 (agree).

\section{Data processing and data analysis Qualitative data}

The qualitative analyses used the procedures and techniques of Grounded Theory [22] (i.e. open coding and axial coding). Grounded Theory is a systematic method to develop a theory or hypothesis about a particular phenomenon, based on people's experiences with and views about this phenomenon. Rather than formulating a hypothesis, the process starts with data collection.

After data collection, all personal information is removed from the test material and audiovisual recordings of verbal expressions are transcribed verbatim. Non-verbal expressions as well as the actual performance on the tasks are described. Observational notes made by the investigator are integrated with the transcriptions as comments in the text. These transcripts are then read and reread by the first author, to extract important fragments of information from the text, and label them with "codes".

Codes (and their information fragments) are grouped into categories, in order to gradually develop a description of the phenomenon. The categories are combined into themes, which are the basis of the theory to be developed. For example, when a participant said "What's all this?!It's happening again!" while looking surprised and confused and laughing sarcastically, this phrase was coded as "frustration about unexpected reactions of software", which was later categorized at a higher level as "negative verbalizations about the software", and was classified under the theme of "responses to the software".

In the current study, data of the first six individuals in each group of participants were read and words or phrases were coded. This first step of data analysis is called open coding (or "exploring the data"). The resulting codes (and their information fragments) provide a first outline of the data and the concepts they entail. After the data of four participants from each group had been assessed, saturation in the open coding phase was reached (the first exploration of the data revealed no relevant categories anymore). This information was then used to process data from additional participants (referred to as "axial coding") to describe in more detail the categories developed in the open coding phase and their interrelations. This was continued until saturation was reached in the axial coding phase (no new information emerged related to the descriptions of the categories), that is, after assessment of the data from ten $\mathrm{ABI}$ patients and eight healthy participants. The data from the remaining respondents (one with $\mathrm{ABI}$ and two healthy participants) were used for selective coding (i.e. selecting the core category, and relating this category to the other categories). The transcripts of these respondents were read and reread in order to distinguish which category appeared frequently in the data, and how it was related to all other categories identified. As a result, two core processes were identified: information processing and task execution. The results of the selective coding phase were compared with earlier processed material to reach a first step in validating the model developed.

This cycle of coding, developing and describing concepts, and formulating additional research questions, was repeated until no more information from supplemental data collection was to be expected.

Dedicated software (Atlas.ti version 5.2 [23]) was used to store and organize the qualitative data.

The quality and validity of the analysis was safeguarded in various ways. Initial coding of the data was done by the first author (EdJ). Co-authors (IP, KS and MvB) participated in coding of transcripts or parts thereof, in the different phases of the data analysis. Differences in coding between the researchers were discussed with the first author to prevent her becoming biased in the coding process and to support the development of concepts and relationships between concepts. During the entire process of data collection and data analysis, a log file was used to record thoughts about additional research questions, decisions, codes, emerging patterns and the two identified core processes. The log file enables other researchers to follow the research process and the decisions made. 


\section{Quantitative data}

Means and standard deviations were calculated and reported for descriptive variables and the task outcome measures (speed, success rate and effort experienced). Because of the relatively small sample size, the number of quantitative analyses was kept to a minimum and interpreted with caution. T-tests and $\chi^{2}$-tests were used to identify group differences, and $\alpha$ was set at 0.05 . No correction for multiple testing was used, in view of the exploratory nature of the study. Statistical analyses were performed with SPSS statistical software (version 19.x for Mac OSX).

\section{Results}

\section{Participant characteristics}

Complete data were obtained from 14 patients with $\mathrm{ABI}$ and 14 healthy participants. Due to time constraints during the home visits, one healthy participant did not perform the

Table I. Participant characteristics $(n=30)$.

\begin{tabular}{|c|c|c|}
\hline Participant characteristics & $\begin{array}{l}\text { ABI patients } \\
\qquad(\mathrm{n}=15)\end{array}$ & $\begin{array}{c}\text { Healthy } \\
\text { participants } \\
(\mathrm{n}=15)\end{array}$ \\
\hline Age in years: mean (SD), [range] & $\begin{array}{c}53.6(9.4) \\
{[35-65]}\end{array}$ & $\begin{array}{l}49.9(10.2) \\
{[26-65]}\end{array}$ \\
\hline Male: number (\%) & $8(53 \%)$ & $8(53 \%)$ \\
\hline Level of education ${ }^{\mathrm{b}}$ : mean (SD) & $4.1(2.2)$ & $4.5(1.6)$ \\
\hline $\begin{array}{l}\text { Computer experience in hours per week: } \\
\text { mean (SD) }\end{array}$ & $15.9(10.1)$ & $17.6(14.2)$ \\
\hline Cognitive functioning $\mathrm{CFQ}^{c}$ : mean (SD) & $47.8(10.3)^{\mathrm{a}}$ & $31.1(8.3)$ \\
\hline VVLT $^{\mathrm{d}}$ total score trial $1-5$ & $39.5(12.2)$ & $45.0(15.0)$ \\
\hline $\mathrm{CST}^{\mathrm{e}}$ part $\mathrm{C}$, two concepts: in seconds & $31.8(13.3)$ & $29.0(10.9)$ \\
\hline
\end{tabular}

T-test: $\mathrm{p}<0.01$

${ }^{\mathrm{b} C l a s s i f i c a t i o n}$ according to the SOI classification by Statistics Netherlands.

${ }^{c}$ CFQ: Cognitive Failure Questionnaire, $(0-100)$ higher score means more com-

plaints.

dVVLT: Visual Verbal Learning Test.

${ }^{\mathrm{e}} \mathrm{CST}$ : Concept Shifting Task. computer tasks and one patient was not interviewed. Table I presents the demographic and clinical characteristics of the participants. The groups did not differ with respect to age, sex, educational level or number of weekly hours of computer experience. Although more cognitive complaints were found in the patient group $(\mathrm{t}(27)=5.05, \mathrm{p}<0.01)$, no significant difference was observed in cognitive task performance, neither on the memory nor on the executive functioning test.

Mean time since brain injury was 9.7 SD 11.2 years. Five individuals had suffered traumatic brain injury, seven had experienced a stroke, two had experienced a subarachnoid haemorrhage and one patient suffered from chronic solventinduced encephalopathy. All lived independently at home.

\section{Qualitative results}

Figure 1 offers a schematic representation of the results. As stated above, two core processes were identified: information processing and task execution. Information processing is necessary to prepare and plan the task execution. Task execution depended on multiple cognitive factors, such as understanding the assignment, remembering what to do, self-monitoring and problem-solving strategies. However, other important factors influencing the execution were emotional responses, as well as fatigue. Finally, external factors such as environmental distractions or unexpected responses from the software also played a role. First the core themes will be described and then the modifying factors that were identified.

The qualitative results are presented as follows: verbal expressions and observations are reported in italics. If quotations are from patients, the code starts with $\mathrm{P}$, if quotations are from healthy participants the code starts with C. All quotations have been provided with case numbers, 1 through 15 . The last number is the corresponding assignment number. Where "users" is indicated, the result applies to both groups. All participants were Dutch; the quotes were translated into

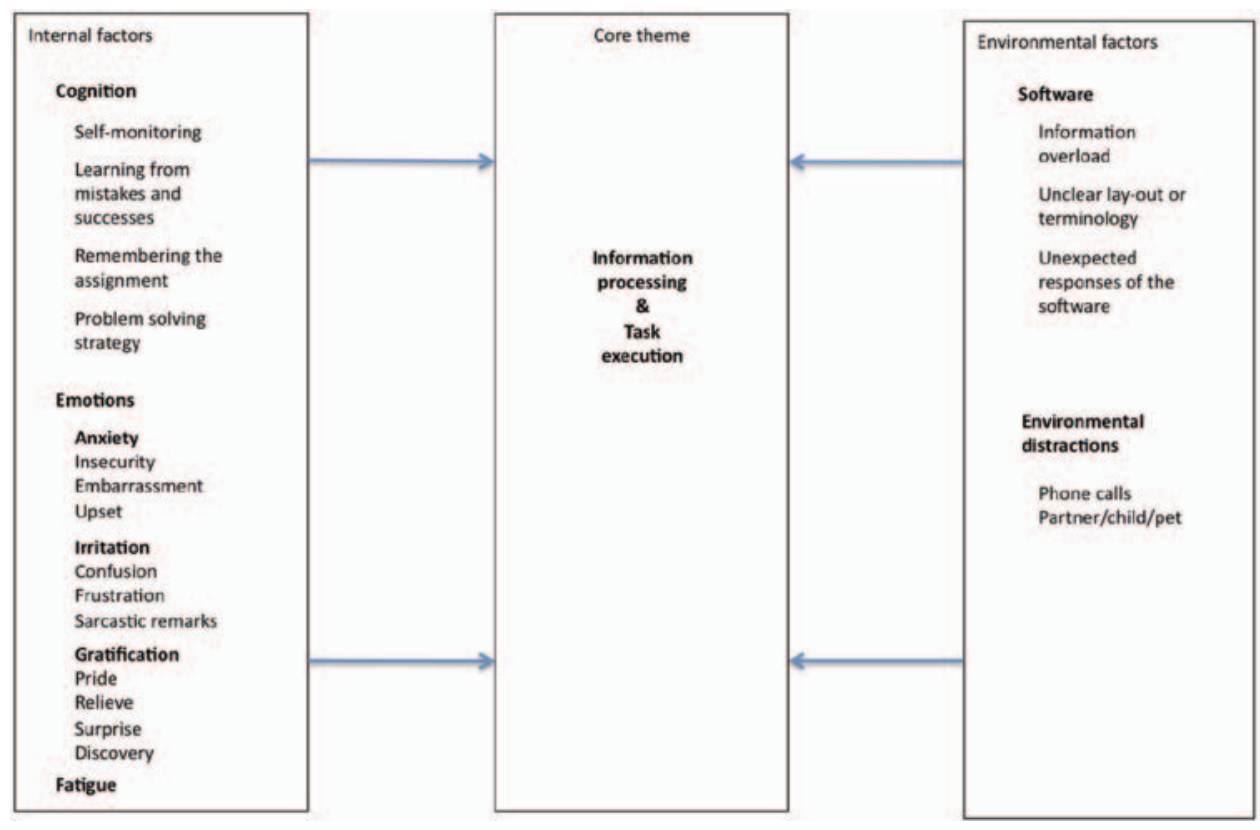

Figure 1. Information processing \& task performance and their influencing factors. 
English. Names were changed to ensure the anonymity of the participants.

\section{Information processing}

Users started each task by reading the assignment at hand. Some users, particularly those in the patient group, reread the assignment several times during the execution of the tasks. Sometimes, parts of the assignment text were not processed at all. For instance, when entering the appointment with a GP, several users entered the address of their own GP, or made up a name and address instead of using the information provided in the task [Reads the assignment again... "Well, yes Dr. Blok, that's my GP"... enters this name ... "erm R. Blok I think, and now... address and phone number... I don't know it by heart... phone number... I don't know... Oh I didn't even see that (information)..oh dear!'] P-09-1.

Instructions sometimes had to be repeated, again especially in the patient group, or were not understood at all. [EdJ: "What if you double-click on the appointment"? P-02: doubleclicks four times on the date in the calendar instead of on the appointment. EdJ: "On the appointment you want to recur?" P-02: "I don't know... No, I don't understand that, that's really hard for me"] P-02-5.

\section{Software: information overload}

The amount of information present on the screen was sometimes difficult to grasp by the users, which led to mistakes in the execution of tasks ["Still, I don't think it's possible, at least I don't see it straightaway"] C-07-2a.

For instance, setting up a recurring appointment requires the use of a separate window with many options to choose from. More than once, users overlooked the last few options, thereby creating a recurring appointment without specifying an end date.

Users in both groups reported feeling overwhelmed by the information at times, and the patients with $\mathrm{ABI}$ in particular sometimes deliberately chose to ignore some parts: ["I see a lot of things, but I can't be bothered with that anymore"] P-05-5.

\section{Remembering the assignment}

Several users found it hard to remember the assignment or parts thereof; they forgot or ignored aspects of the task. Comments about memory difficulties were heard particularly in the patient group ["I'll now go here, to the datebook, and then I go to the 29th of November, I think that was it, I already forgot it again."] P-07-1. But the healthy participants also sometimes needed reminding ["All right, I think it's ok now". EdJ: "Did you also read the second part of the task?" C-01: "Oh right!"] C-01-3.

\section{Learning from mistakes and successes}

Users in both groups were often confused about unexpected responses of the software ["Am I doing something wrong? Am I making a mistake? Why does it do this?"] P-13-1. ["Oh look! I'm already missing half of it again"] P-11-2a. ["What am I doing wrong? Is the font size too large? That is not possible, is it?"] C-09-1. In other cases, users made mistakes that disrupted the correct execution of the task, for instance entering the wrong information (e.g. day of the week) in a recurring appointment. In the patient group, some users referred to their cognitive impairment as a cause of running into problems.

Furthermore, some users, especially in the patient group, failed to remember how to reproduce the steps used in an earlier task, or failed to learn from their mistakes. They therefore had to discover the steps all over again, so it took longer than necessary to complete the task [EdJ: "Do you remember that you double-clicked last time?" P-02: "No! I think that if you go to the datebook, you can see it there"...Clicks on datebook "No, I guess not..."] P-02-5.

\section{Self-monitoring}

Problem solving starts with recognizing a problem. However, the users did not always take notice of problems or mistakes, which was coded as "insufficient self-monitoring”. If users in both groups thought they had successfully solved a problem when in fact they had not, this was coded as "false success". For example, the program has a time limit for entering an appointment by typing the name of the appointment in the calendar, which caused many users to make several appointments for the same timeslot. After the time limit had been exceeded, the possibility to enter text was inactivated by the software, but users kept typing, thus creating another appointment. Users often thought that this problem was caused by using certain keys, or because they left spaces between the words ["I made two appointments by accident again", looks surprised at the screen, scratches his face, thinking. "Oh, so they have to be connected, stay connected?! Aha!"] P-01-2a. Since he thought he had successfully solved this problem, but actually had not, this was coded as "false success".

In other instances, some users in the patient group did not seem to notice their successes, and consequently failed to learn from them, for example when recurring appointments had to be entered in the calendar: ["I don't know how... No, I don't know how to do this." He does not notice that he just successfully entered a repeat pattern for the appointment] P-02-3.

\section{Problem-solving strategy}

When the users noticed problems, they used different problem-solving strategies. The four most frequently used strategies in both groups were "reasoning and goal-oriented searching", "trial and error", "orientation" and "seeking support".

An example of "reasoning and goal-oriented searching" was ["I'm going to try it. First we have to move to the right month... like so... go to the 2nd of February, click on it... and then at two p.m. we type in GP"] C-02-1. "Using trial and error" is illustrated by the following quote ["But... er... how do we get there?" Looks briefly at the top of the screen, clicks on New and opens a new appointment, seems unsure what to do next and closes the window, "No... that's not right"] P-14-2a. An example of "orientation" was: [Looks around in the current window, seems to look for something EdJ: "What are you looking for?"] C-01-4. 
Many users in both groups turned to the investigator for help. ["Am I doing this wrong?... Am I doing it wrong or not? ... Why is it doing this? This program?"] P-13-1.

\section{Anxiety}

During task execution, several negative responses, such as shame and insecurity, were observed in both groups of users. Insecurity or fear of failing was evident, for example, from the number of times, participants checked the correct execution of the task or asked the investigator for help ["Well, what I just did doesn't matter, does it?... I want to... Can I click on this to delete it?... Should I enter it for today, or start tomorrow?"] $P-12-1 / 3$. Some respondents in both groups reported a general negative affect towards computers ["There. That's why I hate computers you know, they never do what I want them to do, and I don't know what they want from me..."] C-02-3.

A few participants even became upset during the test, especially in assignment $2 \mathrm{~b}$, when a new task required them to change a previously made calendar entry. It appeared that individuals with $\mathrm{ABI}$ had a harder time performing this task than healthy participants ["Gosh. Well". Seems insecure... Looks at the investigator and sighs deeply a few times, hands in his hair. "Well, how should I do this..." Looks troubled. "The problem is, I can't combine these two things" Sounds choked up. "This is so horrible... It makes me feel so miserable"] P-09-2b.

It also seemed that some of the users, in both groups, felt ashamed when making mistakes or if they did not know what to do, and a common reaction in these cases was to make jokes or laugh ["It probably isn't the right way... erm... Let's see... Can I get these out of the datebook? These two?" Looks over at the investigator for help, who does not respond "You know it, I don't!" Laughs and sighs] P-13-3. ["Recurs weekly" EdJ: "Does it?" C-15: "Yes, weekly, isn't it? Every day...oh every day, yes, no daily, sorry!" Laughs a little and looks over at the investigator] C-15-3.

\section{Irritation}

During the execution of the tasks, most of the respondents in both groups seemed frustrated at times. They would respond to the investigator in a brusque fashion, curse or make noises indicating frustration. This behaviour was often elicited by an unexpected reaction from the software ["Sure! Now, this happens again! It's still there?! Why?"] P-01-2b. ["Why!" Clicks tongue and raises her arm (as an expression of frustration and confusion) "This one must go there! There!"] C-14-2b.

Respondents also made sarcastic comments about the software or about themselves, expressing frustration. This was more pronounced in the patient group [Reads assignment... Sighs... "Nice, real nice (!) Let's take a gamble."] P-05-1. ["You really got the computer nerd of the year now!" Laughs sarcastically] P-12-1. ["I'm too stupid for this"] P-07-1.

\section{Pleasure}

Not all reactions were negative: positive responses such as pride, relief, surprise and discovery were also encountered in both groups, often after successful execution of an assignment ["Yes! Well done Robert" (Talks to himself)... "Every Tuesday and Thursday is entered now. OK! That's it. Yes!" Laughs and sighs in relief] P-05-4.

\section{Fatigue}

Users became tired towards the last two assignments, with individuals with ABI seeming to get tired sooner and less gradually than healthy participants ["It's all over now, you know?" Sighs. EdJ: "Are you exhausted?" P-13: "Yes..it's all done." Laughs a little] P-13-4. Users yawned and sighed more during the later assignments. It seemed harder for them to reason and solve problems; they listened less to instructions and became more irritable. Other users stared at the screen and turned silent. A few ABI individuals reported inability to proceed; in these cases, and in cases where the investigator did not expect successful completion, the assignment was aborted [EdJ: "All right, let's leave it at this because we've taken quite a long time already." P-05: "Yes, it's becoming quite erm..." EdJ: "Complicated eh?" P-05: "Yes, it's starting to get really confusing and complex"] P-05-5.

\section{Unclear screen layout and terminology}

Complaints about the screen layout or the use of terminology were rare in both groups and focused on the size of the letters on the screen and the use of ambiguous terminology which would be more suitable for use in an office environment ["What do they mean by meeting? I didn't enter a meeting? Who entered this? Start meeting, end of meeting... Oh tiny print!'] P-01-1/3.

\section{Environmental distractions}

Because the test setting was the participant's home, there were some distractions, such as the presence of other people in the room, or telephone calls. Some users, especially ABI patients, referred to these distractions as the reason for their inability to focus on the execution of the task ["Yes... See, this is very hard, that noise there... I'm not listening to it, but, it... it makes me..."] P-04-1.

\section{Quantitative results}

Table II shows the execution times in both groups for each task. Execution time on the last of the five tasks was significantly longer for the ABI-group than for the group of healthy participants $(\mathrm{t}(19)=-2.64, \mathrm{p}<0.05)$.

The proportions of participants who successfully completed the task, failed or did not execute the whole task (Table III) show that healthy participants were more successful than ABI patients $\left(\chi^{2}(4)=6.51, \mathrm{p}<0.05\right)$.

The mental effort scale showed that the ABI group reported more effort on all assignments; the differences were significant for task $2 \mathrm{a}(\mathrm{t}(27)=-3.25, \mathrm{p}<0.01)$, task $4(\mathrm{t}(26)=-2.47, \mathrm{p}<$ $0.05)$ and task $5(\mathrm{t}(20)=-2.17, \mathrm{p}<0.05)$ (Table IV). Because more patients than healthy participants did not perform the last task (due to time constraints or fatigue), the number of effort scales for the last task differed between both groups.

In the second semi-structured interview, after the participants had done the tasks, statements on how easy it was to use the software were responded to as follows (Table V). Healthy participants were more positive than $\mathrm{ABI}$ patients about the 
Table II. Time needed to execute each task (in seconds).

\begin{tabular}{lcc}
\hline & $\begin{array}{c}\text { ABI patients } \\
(\mathrm{n}=15)\end{array}$ & $\begin{array}{c}\text { Healthy } \\
\text { participants } \\
(\mathrm{n}=14)\end{array}$ \\
\hline $\begin{array}{l}\text { 1. Single appointment with fixed time, } \\
\text { mean (SD) }\end{array}$ & $337.8(168.6)$ & $323.7(157.6)$ \\
$\begin{array}{l}\text { 2a. Single appointment with flexible time, } \\
\text { mean (SD) }\end{array}$ & $241.2(157.7)$ & $197.3(120.5)$ \\
$\begin{array}{l}\text { 2b. Single appointment interfering with } \\
\text { task 2a, mean (SD) }\end{array}$ & $170.1(93.5)$ & $264.6(173.9)$ \\
$\begin{array}{l}\text { 3. Appointment recurring every day, } \\
\text { mean (SD) }\end{array}$ & $576.7(242.0)$ & $502.6(244.2)$ \\
$\begin{array}{l}\text { 4. Recurring appointment with exceptions } \\
\text { mean (SD) }\end{array}$ & $534.6(222.6)$ & $580.4(229.5)$ \\
$\begin{array}{l}\text { 5. Recurring series of appointments, } \\
\text { mean (SD) }\end{array}$ & $771.8(235.6)^{\mathrm{a}}$ & $542.3(82.9)$ \\
\hline aT-test: $\mathrm{p}<0.05$. & & \\
\hline
\end{tabular}

Table III. Proportions of successful versus failed task execution over all tasks.

\begin{tabular}{lcc}
\hline & ABI patients $(\mathrm{n}=15)$ & Healthy participants $(\mathrm{n}=14)$ \\
\hline Success & 0.59 & 0.77 \\
Failure & 0.41 & 0.23 \\
\hline
\end{tabular}

$\chi^{2}(4)=6.51, \mathrm{p}<0.05$.

Table IV. Mental effort scale (0-150).

\begin{tabular}{|c|c|c|}
\hline & $\begin{array}{l}\text { ABI patients } \\
\qquad(\mathrm{n}=15)\end{array}$ & $\begin{array}{c}\text { Healthy } \\
\text { participants } \\
(\mathrm{n}=14)\end{array}$ \\
\hline $\begin{array}{l}\text { 1. Single appointment with fixed time mean } \\
\text { (SD) }\end{array}$ & $57.8(30.3)$ & $39.8(23.5)$ \\
\hline $\begin{array}{l}\text { 2a. Single appointment with flexible time } \\
\text { mean (SD) }\end{array}$ & $53.1(27.3)^{\mathrm{b}}$ & $26.1(16.3)$ \\
\hline $\begin{array}{l}\text { 2b. Single appointment interfering with task } \\
\text { 2a mean (SD) }\end{array}$ & $48.7(35.0)$ & $40.6(25.9)$ \\
\hline $\begin{array}{l}\text { 3. Appointment recurring every day mean } \\
\text { (SD) }\end{array}$ & $64.2(26.5)$ & $55.9(28.5)$ \\
\hline $\begin{array}{l}\text { 4. Recurring appointment with exceptions } \\
\text { mean (SD) }\end{array}$ & $72.2(23.5)^{\mathrm{a}}$ & $50.0(23.7)$ \\
\hline $\begin{array}{l}\text { 5. Recurring series of appointments mean } \\
\text { (SD) }\end{array}$ & $84.8(23.6)^{\mathrm{a}}$ & $58.9(32.2)$ \\
\hline
\end{tabular}

Table V. Scores ${ }^{\mathrm{a}}$ on statements about the ease of use of standard calendar software.

\begin{tabular}{|c|c|c|}
\hline & $\begin{array}{l}\text { ABI patients } \\
\quad(\mathrm{n}=12)\end{array}$ & $\begin{array}{c}\text { Healthy } \\
\text { participants } \\
(\mathrm{n}=14)\end{array}$ \\
\hline $\begin{array}{l}\text { The calendar software was transparent, mean } \\
\text { (SD) }\end{array}$ & $2.8(1.3)^{b}$ & $4.0(0.9)$ \\
\hline Entering tasks was easy, mean (SD) & $2.7(1.0)^{\mathrm{b}}$ & $3.7(1.1)$ \\
\hline Adjusting tasks was easy, mean (SD) & $2.8(1.2)^{\mathrm{b}}$ & $4.1(0.5)$ \\
\hline Finding tasks was easy, mean (SD) & $3.6(1.2)$ & $4.0(1.0)$ \\
\hline Entering notes was easy, mean (SD) & $3.5(1.5)$ & $4.1(1.0)$ \\
\hline Entering recurring tasks was easy, mean (SD) & $2.8(1.0)$ & $3.5(1.3)$ \\
\hline $\begin{array}{l}\text { My opinion about calendar software has } \\
\text { changed, mean (SD) }\end{array}$ & $2.9(1.4)$ & $2.7(1.4)$ \\
\hline $\begin{array}{l}\text { I'm going to use calendar software myself, } \\
\text { mean (SD) }\end{array}$ & $2.8(1.5)$ & $2.6(1.3)$ \\
\hline \multicolumn{3}{|l|}{$\begin{array}{l}\text { aLLikert scale (1 (disagree)-5 (agree)). } \\
\text { bT-test: } \mathrm{p}<0.01 .\end{array}$} \\
\hline
\end{tabular}

transparency of the software $(\mathrm{t}(24)=2.76, \mathrm{p}<0.05)$. Healthy participants were also more positive about the ease of entering $(\mathrm{t}(24)=2.49, \mathrm{p}<0.05)$ and adjusting $(\mathrm{t}(24)=3.88, \mathrm{p}<$ $0.01)$ tasks in the calendar. No differences between the groups were found for other statements, regarding the ease of entering recurring tasks, finding tasks in the calendar and adding notes. Both groups were neutral to positive about these three statements. Finally, both groups were ambivalent on whether using the calendar software had changed their opinion about it and if they were more likely to use it in the future.

\section{Discussion}

Since the suitability of standard calendar software for people with $\mathrm{ABI}$ had not been systematically investigated so far, the actual use by ABI patients and by healthy participants was compared, using both qualitative and quantitative methods.

At first glance, the qualitative results show general similarities between healthy participants and ABI patients in terms of using standard calendar software. Both groups struggled with the same kind of difficulties, such as information overload due to the amount of information presented on the screen, or the experience of frustration when the software responded in an unexpected way. A closer look shows, however, that ABI patients were more likely to show these difficulties during task performance (e.g. rereading the assignment or showing symptoms of fatigue) or reacted more strongly (e.g. became upset or made sarcastic comments).

The quantitative results show that, overall, the healthy participants were more successful than ABI patients. They tended to need less time for most tasks and required less mental effort to perform a task. ABI patients regarded the software as less clear and easy to use than the healthy participants did.

Both the qualitative and the quantitative results showed the same pattern: ABI patients were as able as healthy participants to use standard calendar software, but they seemed to become upset more easily, needed more effort and got tired sooner and more suddenly.

No previous research into calendar software use by ABI patients exists. Still, evidence from other user groups with cognitive difficulties (people with disabilities, dementia, and elderly people) shows that they were able to learn how to manipulate computer programmes, although they needed more time and effort [24], and that they were able to retain this information over time [25]. The greater sensitivity to stress (irritation/anxiety) and difficulty in understanding the responses of the software that is found in ABI patients in the current study was also observed in patients with dementia when using everyday technology [26].

\section{Implications for use of calendar software in a clinical setting}

The results of this study could be used to guide the development of dedicated software for people with cognitive difficulties, in particular individuals with ABI. It is important to keep the specific difficulties for ABI patients in mind 
when designing dedicated software for this group of users, by adopting a user-centred approach [14,27]. Examples of dedicated software on mobile devices for this user group are PEAT [28] and the Handifon [29]. Like others [30,31], this study showed that processing a large amount of information at once or in a short stretch of time is difficult for ABI patients. A distraction-free interface, in which only a small amount of (relevant) information is presented at a time, could therefore improve the user-friendliness of calendar software for this population. Other aspects of the software could also be adapted to the needs of ABI patients. For instance, stepwise serial data entry would mean less of a burden on working memory capacity. Indeed, general rules for human-computer interface design stress the importance of reducing short-term memory load [32]. Impairments in memory functioning also impeded successful use of calendar software in the current study: users often had difficulties remembering which steps to take to enter an appointment. Therefore, consistency in the sequence of actions required to perform a task, including contextual help and limited entry options, could improve the user-friendliness of AT. For example, instead of the option of entering an appointment in several different ways (using menus, short-cut keys or double-click options), it might be better to limit the dataentry methods and offer users one straightforward method.

Training users how to cope with the difficulties they may encounter with standard calendar software could also be an effective way to improve the actual use. Our results suggest that training should focus on coping with internal factors such as cognitive difficulties and emotional reactions, as well as fatigue. Cognitive psycho-education and support could help ABI patients to tackle tasks more efficiently. For example, patients could be taught to first write down the important aspects of the task, so they remember to enter all information. Emotional support could help ABI patients deal with frustration or fear of failing. Since fatigue is very common in ABI patients [33], they could benefit from learning to limit the time they spent entering appointments in the calendar. Finally, knowledge about the influence of environmental factors (e.g. presence of other people or pets, telephone calls) and learning ways to cope with these distractions as well as with unexpected responses of the software itself, could also benefit individuals with $\mathrm{ABI}$ in the use of AT.

\section{Strengths and limitations of the current study}

Design specifications for calendar software products for ABI patients on the market are merely based on assumptions, since previous research for this user group is not available. The results of the present study can guide future software development for patients with $\mathrm{ABI}$ and thereby stimulate the implementation of AT in the clinical practice of cognitive rehabilitation and beyond.

Combining qualitative and quantitative methods in a mixed methods design enabled us to compare the results of these two methods, and the results were complementary. The results of the two methods show that although healthy participants and $\mathrm{ABI}$ patients have similar reaction patterns, the second group has greater difficulties, need more effort, are more easily upset and become fatigued sooner.

A larger sample would have improved the statistical power for the quantitative measures in this study. It was, however, difficult to enroll more participants, partly due to the relatively large time investment (2-hour visit). This may have caused selection bias, which may have influenced the results. More severely affected patients may not have been asked to participate, which could explain the absence of performance differences between healthy participants and ABI patients in the neuropsychological tests. However, the ABI patients did report more cognitive complaints

"Thinking aloud", the technique that was used to gain more insight into the reasoning about and planning of the assignments, requires certain skills, which might not be equally present in patients and healthy participants. For instance, ABI patients may lack the necessary insight into their own reasoning, or fail to understand the specific causes and effects of their own actions. This may have caused a reduced capacity for introspection, compared to that of healthy participants. Lack of insight (anosognosia) is a well-known symptom in a small group of patients in the acute phase after brain injury [34]. However, in our heterogeneous sample of ABI patients, who were no longer in the acute phase, it may be assumed that only a small minority, if any, of the patients will have suffered from this symptom.

\section{Considerations for future research}

Both groups of users had limited or no experience with the software at hand, which may explain the lack of major differences between the groups. It is possible that clearer differences would have emerged if both groups had been more accustomed to the software. Therefore it could be interesting to explore the variability of group differences over time when this software is used on a regular basis.

The clearest differences between the groups emerged during the last two (most difficult) tasks. One could argue that in future research, a heavier task load from the start might lead to more differentiated results. Inclusion of more severely affected ABI individuals could yield more information about the influence of the extent of cognitive impairment on the use of AT.

AT use in cognitive rehabilitation is an exciting area of research and one that requires a strong multi-disciplinary input to design, develop and implement user-centred solutions.

Declaration of Interest: This project was supported by a grant (grant no. 14350052) from the Netherlands Organization for Health Research and Development (ZonMW) The Hague, The Netherlands. The authors report no conflicts of interest.

\section{References}

1. McDonald BC, Flashman LA, Saykin AJ. Executive dysfunction following traumatic brain injury: neural substrates and treatment strategies. NeuroRehabilitation 2002;17:333-344.

2. Anderson CA, Arciniegas DB. Cognitive sequelae of hypoxic-ischemic brain injury: a review. NeuroRehabilitation 2010;26:47-63. 
3. Vakil E. The effect of moderate to severe traumatic brain injury (TBI) on different aspects of memory: a selective review. J Clin Exp Neuropsychol 2005;27:977-1021.

4. Evans JJ, Wilson BA, Needham P, Brentnall S. Who makes good use of memory aids? Results of a survey of people with acquired brain injury. J Int Neuropsychol Soc 2003;9:925-935.

5. Hart T, Buchhofer R, Vaccaro M. Portable electronic devices as memory and organizational aids after traumatic brain injury: a consumer survey study. J Head Trauma Rehabil 2004;19:351-365.

6. Gentry T, Wallace J, Kvarfordt C, Lynch KB. Personal digital assistants as cognitive aids for individuals with severe traumatic brain injury: a community-based trial. Brain Inj 2008;22:19-24.

7. de Joode E, van Heugten C, Verhey F, van Boxtel M. Efficacy and usability of assistive technology for patients with cognitive deficits: a systematic review. Clin Rehabil 2010;24:701-714.

8. Depompei R, Gillette Y, Goetz E, Xenopoulos-Oddsson A, Bryen D, Dowds M. Practical applications for use of PDAs and smartphones with children and adolescents who have traumatic brain injury. NeuroRehabilitation 2008;23:487-499.

9. Hart T, O’Neil-Pirozzi T, Morita C. Clinician expectations for portable electronic devices as cognitive-behavioural orthoses in traumatic brain injury rehabilitation. Brain Inj 2003;17:401-411.

10. De Joode EA, van Boxtel M, Verhey F,van Heugten C. Use of assistive technology in cognitive rehabilitation: opinions and expectations of health care professionals and potential users. Manuscript submitted for publication.

11. O’Neil-Pirozzi TM, Kendrick H, Goldstein R, Glenn M. Clinician influences on use of portable electronic memory devices in traumatic brain injury rehabilitation. Brain Inj 2004;18:179-189.

12. Boman IL, Tham K, Granqvist A, Bartfai A, Hemmingsson H. Using electronic aids to daily living after acquired brain injury: a study of the learning process and the usability. Disabil Rehabil Assist Technol 2007;2:23-33.

13. Manly T, Hawkins K, Evans J, Woldt K, Robertson IH. Rehabilitation of executive function: facilitation of effective goal management on complex tasks using periodic auditory alerts. Neuropsychologia 2002;40:271-281.

14. Scherer MJ. Assessing the benefits of using assistive technologies and other supports for thinking, remembering and learning. Disabil Rehabil 2005;27:731-739.

15. Ohman A. Qualitative methodology for rehabilitation research. J Rehabil Med 2005;37:273-280.

16. Kroll T, Neri MT, Miller K. Using mixed methods in disability and rehabilitation research. Rehabil Nurs 2005;30:106-13; discussion 113.

17. Lezak M, Howieson DB, Loring DW. Neuropsychological Assessment. 4th Edition. New York: Oxford University Press; 2004.

18. Van der Elst W, Van Boxtel MP, Van Breukelen GJ, Jolles J. The Concept Shifting Test: adult normative data. Psychol Assess 2006;18:424-432.

19. Ponds R, van Boxtel M, Jolles J. The 'Cognitive Failure Questionnaire' as a measure for subjective cognitive functioning (in Dutch). Tijdschrift voor Neuropsychologie 2006;1:37-45.

20. De Bie SE. Standard questions 1987: Proposal for uniformization of questions regarding background variables and interviews (in Dutch). Leiden: Leiden University Press.

21. Zijlstra FRH, van Doorn L. The construction of a scale to measure perceived effort. (Technical Report). Delft: University of Delft; 1985.

22. Strauss AL, Corbin JM. Basics of qualitative research: Grounded theory procedures and techniques. 2nd Edition. Thousand Oaks, CA: Sage; 1998.

23. Friese S., ATLAS.ti., Thomas Muhr, Scientific Software Development: Berlin, Germany; 2004.

24. Glisky EL, Schacter DL, Tulving E. Computer learning by memoryimpaired patients: acquisition and retention of complex knowledge. Neuropsychologia 1986;24:313-328.

25. Glisky EL, Schacter DL. Long-term retention of computer learning by patients with memory disorders. Neuropsychologia 1988;26:173-178.

26. Nygård L, Starkhammar S. The use of everyday technology by people with dementia living alone: mapping out the difficulties. Aging Ment Health 2007;11:144-155.

27. Sohlberg MM, Fickas S, Ehlhardt L, Todis B. The longitudinal effects of accessible email for individuals with severe cognitive impairments. Aphasiology 2005;19:651-681.

28. Levinson R. The Planning and Execution Assistant and Trainer (PEAT). J Head Trauma Rehabil 1997;12:85-91.

29. Abilia. Handifon. 2011 [cited 2011; Available from: http://www.abilia. org.uk].
30. Ruttan L, Martin K, Liu A, Colella B, Green RE. Long-term cognitive outcome in moderate to severe traumatic brain injury: a meta-analysis examining timed and untimed tests at 1 and 4.5 or more years after injury. Arch Phys Med Rehabil 2008;89:S69-S76.

31. Barker-Collo S, Feigin VL, Parag V, Lawes CM, Senior H. Auckland Stroke Outcomes Study. Part 2: Cognition and functional outcomes 5 years poststroke. Neurology 2010;75:1608-1616.

32. Shneiderman B. Designing the User Interface - Strategies for Effective Human-Computer Interaction. 2nd edition. Reading, MA: AddisonWesley Publishing Company; 1992.

33. Johansson B, Berglund P, Rönnbäck L. Mental fatigue and impaired information processing after mild and moderate traumatic brain injury. Brain Inj 2009;23:1027-1040.

34. Starkstein SE, Jorge RE, Robinson RG. The frequency, clinical correlates, and mechanism of anosognosia after stroke. Can J Psychiatry 2010;55:355-361.

\section{Appendix 1}

\section{Assignment 1}

You have just made an appointment with your GP for April 14th 2011, from 2 to 2.30 p.m.

A. Put this appointment in your electronic calendar.

B. Include the name, address and telephone number of your $\mathrm{GP}^{*}$.

C. As you want to remember to ask for a repeat prescription of your medication, add a separate note.

\section{Assignment 2a}

Tomorrow you want to do your shopping. This has to be done between 10 and 12 in the morning; it will take you one hour.

A. Enter this task in your electronic calendar.

B. Be sure to include your shopping list* .

\section{Assignment 2b}

Your next-door neighbour just came by and asked you to come over tomorrow between 10 and 11 a.m. to have coffee with her.

A. You have accepted this invitation, so enter this appointment in your electronic calendar.

B. Make sure you have time left to do your shopping before noon.

\section{Assignment 3}

Every day you have lunch from noon to 1 p.m. - it usually takes you one hour. When you are very busy, half an hour is enough.

A. Enter this lunch break in your electronic calendar, adding an alarm, for every day of the coming week.

B. You have promised a neighbour to help him plant a tree in his backyard on Thursday. He asked you to be there at 12.30 p.m. Make an entry in your electronic calendar for this appointment.

C. See to it that you have lunch before you go to the neighbour's.

*This information was provided with the assignment. 


\section{Assignment 4}

Starting next Tuesday, you are going to take a course on photography. The classes are every Tuesday and Thursday, from 7 to 9 p.m.

A. Enter these appointments in your calendar, up to and including the last class on April 12th.

B. The class of March the 31st will be cancelled and will be transferred to April 1st. Adjust the appointments in your calendar.

C. There will be a return visit on Tuesday 26th April, at the usual time. Enter this in your calendar too.

\section{Assignment 5}

Because you tend to forget to switch off the central heating or your computer at night, you have decided to put your evening's routine in your calendar.

Put these tasks down in your calendar for the next 3 days. Please add an alarm to each of them:
A. 8:00 p.m. close shutters
B. 10.00 p.m. lower heating
C. 10.05 p.m. switch off TV and other appliances
D. 10.10 p.m. lock and bolt front door
E. 10.15 p.m. switch off computer

\section{Appendix 2}

Mental effort scale

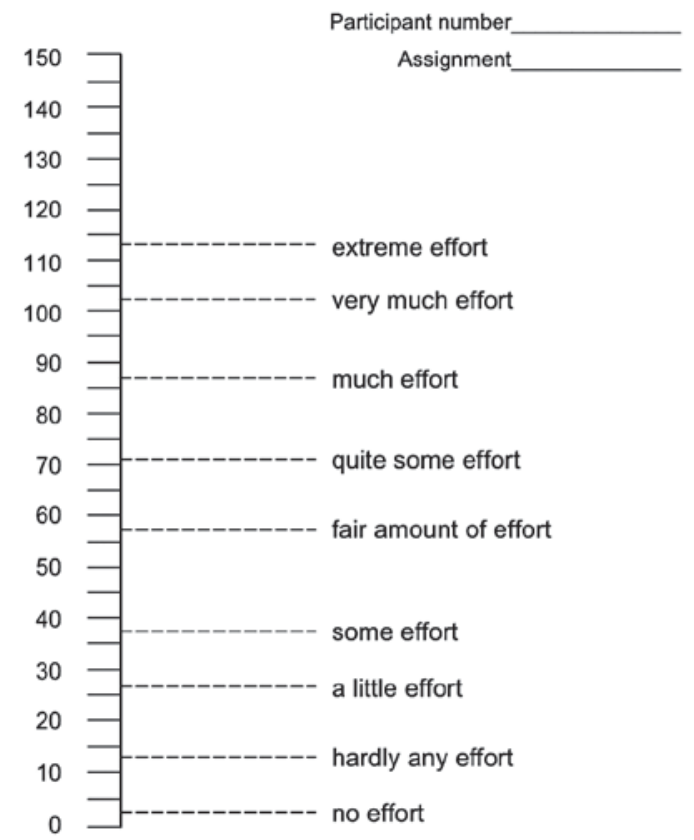

